\title{
Factors Affecting Quality of Health Care among Old Adults at Beni-Suef University Hospital
}

\author{
Mohammed Hassan Amine', Mohamed Yasser Saif ${ }^{2}$, Noha Ahmed Mohamed ${ }^{3}$ \\ ${ }^{1}$ Master Student at Faculty of Nursing, Beni-Suef University, ${ }^{2}$ Professor of Ophthalmology, Faculty of Medicine, \\ Beni-Suef University, ${ }^{3}$ Assist. Professor of Community Health Nursing Faculty of Nursing, Beni-Suef University
}

\begin{abstract}
Background: Aging is the process of progressive change in the biological, psychological and social structure of individuals'. Quality is affected by both the technical performance of providers and the extent to which a system reaches those in need.
\end{abstract}

Aim of Study: The study aimed to assess the quality of health care delivered to old age and factors affecting quality of health care.

Subjects and Method: The study was conducted in the inpatient units at Beni-Suef university hospital. Study sample were nurses and patients: For nurses; all nurses who have experience more than one year at medical surgical department, urinary tract diseases, and provide care for geriatric patients was included in this study. For patients; convenient sample from the pre mentioned setting. Two data collection tools were used to carry out the current study namely; structured Interviewing questionnaire and observational checklists.

Results: $26 \%$ of the nurses were satisfied according to work place satisfaction, the same was percent unsatisfied according to work place satisfaction, and the rest of them $(48 \%)$ had average level of satisfaction. $58 \%$ of nurses had unsatisfied level according to their performance. (42\%) of participants had satisfied level according to their performance.

Conclusion and Recommendations: $38 \%$ of patients had fair level about their evaluation, $33 \%$ of them had excellent level about their evaluation to quality of health care, and $29 \%$ of them had average level and $41 \%$ of them had negative level of satisfaction. Periodic assessment of nurses > perception about quality of care of elderly patient. Regular implementation of training programs regarding quality of care.

Keywords: Factors, Quality, Health Care, Old adults.

\section{Introduction}

Over the past century, truly remarkable changes have been observed in the health of older persons throughout the world, and these changes have strongly impacted society. The growth of the older population

\section{Corresponding Author:}

Mohammed Hassan Amine

Master Student at Faculty of Nursing, Beni-Suef

University, Minia, Egypt

e-mail: m.elkordy@yahoo.com has resulted mostly from a general increase in the overall population size but is also strongly influenced by major declines in leading causes of mortality. These demographic transformations reverberate in society, increasing medical care and social needs, which are expected to increase steeply in the years to come ${ }^{(1)}$.

Egypt is the most populous country in the Middle East and the third-most populous on the African continent (after Nigeria and Ethiopia). One of the main features of the Egyptian population over the last few decades is the gradual increase in the absolute and relative numbers of older people. This trend is expected to continue over the next decades ${ }^{(2)}$. 
This means that, around 20 million Egyptians will be categorized as elderly by that time, this is a big number that resembles a full nation at some parts of the world. There is an urgent need for the implementation of a national policy for elderly care. Although such policies exist, the effectiveness of existing policies and the role of national committees need to be evaluated in order to revive and mobilize the resources available. Older people, as stakeholders, are expected to participate in the implementation of the national policy through all phases of planning, intervention, and evaluation ${ }^{(3)}$.

In addition, there is the migration within the country from rural to urban areas, leaving the elderly behind. This causes variation in the distribution of the aged population within the Egyptian governorates. According to the last Egyptian census, the absolute total number of the elderly is greater in rural areas than urban ones, in spite the fact that their percentage in more in urban (7.18\%) than rural (5.6\%). The policy making bodies in Egypt, mainly the Ministry of Health and Population, Ministry of social Solidarity, the universities and the academic institutions have been long acting to cope with the population ageing ${ }^{(4)}$.

As more people live to advanced old age, these demographic changes imply much more than just an increase in chronic morbidity. The same age related susceptibility that leads to the occurrence of multiple chronic conditions in the same individual causes decrements in functional abilities as well as social and psychologic problems that may have an impact on many facets of their wellbeing and quality of life. Going beyond the demographic focus of counting and projecting the number of older people in the population, epidemiology has made additional contributions to our understanding of the health status and functional trajectory of older individuals ${ }^{(5)}$.

Objective measures of physical performance have received increased attention as assessments that can measure functioning in a standardized manner in research and clinical settings. These measures can be used to represent impairments or actual disability, but most are indicators of functional limitations. Objective performance measures also provide a means of comparing functional status over time or across countries or cultures, whereas disability measures may lose comparability because of environmental differences or differential access to assistive devices ${ }^{(6)}$.
This is clearly an essential aspect of quality of care and is exemplified by approaches taken by Professional Review Organizations in developing programs for quality assurance of inpatient care for Medicare beneficiaries. Other aspects of quality of care that require greater prominence and that are readily accommodated within the categories, structure, process, and outcome, are oriented toward prevention and a consideration of how a system of care is functioning, not only with respect to those who appear for care at the time they do so, but also in terms of the need that exists in a community or general population ${ }^{(7)}$.

A comprehensive assessment of quality of care would be concerned with all three components and their interrelationship, with the ultimate measure of quality determined by the outcome of care. In practice, there are often severe constraints in linking particular structural factors and processes of care to specific measures of health status. Standards for many elements of structure are based on professional judgments and are used for such purposes as accreditation, licensing, Medicare certifications, and establishing qualifications for staff in, for example, hospitals, group practices, and nursing homes ${ }^{(8)}$.

However, standards do not always represent a consensus; they are subject to change as new knowledge is acquired and new technology developed, and different structural patterns may achieve similar levels of quality. Furthermore, the fact that standards are met does not provide assurance that a favorable effect on health status will follow. In short, structural factors such as the availability of highly qualified primary care providers, specialists and support services, or regionalized emergency medical service systems may increase the probability of receiving high-quality care, but they are not sufficient conditions for determining quality ${ }^{(9)}$.

Process of care measures provide more generally accepted indicators of quality of care, reflecting as they do what care is delivered and how. The measures are derived mainly from professional norms of practice or research in which some link to outcome is implicitly or explicitly expected, whether this is improved functioning, delay in dependency, or relief from pain or depression. The degree of certainty about a link may be weak in some cases because of lack of information about the natural history of disease, the relative effectiveness of alternative treatment modalities, or the role of behavioral 
and biological characteristics of patients in determining the course of illness ${ }^{(1)}$.

The selection of process measures for assessing quality of care seeks to minimize these limitations. Measures are available or being developed that range from adherence to algorithms for the treatment of specific conditions to communication and counseling (Inui and Carter, 1985), detection of need for health services, matching need with appropriate sources of care in acute episodes of illness and in long-term care, for which coordination of services is important ${ }^{(5)}$.

Significance of study: The number of older persons in the world is projected to be 1.4 billion in 2030 and 2.1 billion in 2050, and could rise to 3.1 billion in 2100 . Globally, the number of persons aged 80 or over is projected to triple by 2050, from 137 million in 2017 to 425 million in 2050 . Poor patient care, safety and fall are the leading causes of fatal and nonfatal injuries among persons aged ${ }^{(10)}$.

Provision of quality assured health-care services for the elderly population is a challenge that requires joint approach and strategies in addition to cooperation of all health team and the nurses are the corners stone of health care. Understanding quality of care can help nurses recognize problems and provide nursing interventions that will help aging individuals successfully meet the developmental tasks. As well as Optimal care must be delivered to minimize the time spent in the acute care setting. Avoiding costly complications and focusing on health promotion rather than disease management ${ }^{(8)}$.

\section{Aim of the study:}

The aim of this study is to assess the quality of health care delivered to old age and factors affecting quality of health care through assessing the following:

- Level of health care provided to older adult (from patients' perspective)

- Nurses' job satisfaction

- Leadership and management skills (from nurses' perspective)

- Nurses performance

- Safety measures and environmental setting

\section{Subjects and Method}

Research design: Descriptive research design was used in carrying out the current study.
Setting: This study was conducted in in the inpatient units at Beni-Suef university hospital. These settings were having both sexes male and female; Having flow of older adults seeking the foundation service. All settings following the same strategies of care delivery. Consists of two unit's male and female unit.

Subjects: Subjects in this study were nurses and patients: For nurses; all nurses have experience more than one year at medical surgical department, urinary tract diseases and provide care for geriatric patients was included in this study.

For patients; convenient sample will be selected from the pre mentioned setting according to the following criteria; The older adult is already diagnosed with multi comorbidities disease', receiving medical and nursing care for at least 3 months and stay 3 days or more. Fully oriented to place,

Data collection tools: Two data collection tools were used to carry out the current study namely; Structured Interviewing questionnaire and Observational checklists.

Tool 1: Structured Interviewing Questionnaires: include five parts

1. Demographic characteristics of the nurses and patients such as (age, sex, social status level of education, etc.).

2. Healthqual to assess quality of health care developed by the researcher based on related literature.

3. Patient assessment of health care (PAHC) to assess level of health care provided to older adult (from patient' perspective), questionnaire adopted by the researcher based on related literature

4. Nursing workplace satisfaction questionnaire (NWSQ) to assess nurses' job satisfaction developed by the researcher based on related literature

5. Leadership and management skills questionnaire filled by nurses by the researcher based on related literature

Tool 2: Observational checklist includes two parts

Part I: Six Dimensions Scale of Nurses Performance: It was developed by the researcher based on related literature 
Part II: Safety measures and environmental setting: It was developed by the researcher based on related literature

Scoring system: Each item was scored 1 for use and 0 for not use.

Part III: Environmental safety checklist developed by the researcher to assess environmental safety and sanitation condition. The items of this checklist were filled once by the researcher with the assistance of the safety engineers and it declare the absence and the presence of safety measures.

\section{Patient Assessment of Health Care-PAHC:}

- This tool consists of 14 items in the form of three points Likert scale as the following Never (1), Sometimes (2), and Usually (3) and the final score is the sum of the 14 items, ranging from 14 to 42. These scores will be converted to percent and categorized as the following acceptable health care condition $(\geq 60 \%)$ and unacceptable health care condition $(<60 \%)$.

\section{Leadership and management skills questionnaire:}

- This tool consists of 16 items in the form of three points Likert scale as the following Never (1), Sometimes (2), and Always (3) and the final score is the sum of the 16 items, ranging from 16 to 48. These scores will be converted to percent and categorized as the following adequate leadership and management skills $(\geq 60 \%)$ and inadequate leadership and management skills $(<60 \%)$.

\section{Health qual items patient perspective:}

- This tool consists of 20 items in the form of three points Likert scale as the following Fair (1), Good (2), and Excellent (3) and the final score is the sum of the 20 items, ranging from 20 to 60 . These scores will be converted to percent and categorized as the following acceptable quality level $(\geq 60 \%)$ and unacceptable quality level $(<60 \%)$.

\section{Environmental safety:}

- This tool consists of 33 items in the form of "Yes" (1) and "No" (Zero) and the final score is the sum of the 33 items, ranging from 0 to 33. These scores will be converted to percent and categorized as the following safe environment $(\geq 60 \%)$ and unsafe environment $(<60 \%)$.

\section{Nursing Workplace Satisfaction Questionnaire (NWSQ):}

- This tool consists of 15 items in the form of three points Likert scale as the following Disagree $(0)$, partially agree (1), and agree (2) and the final score is the sum of the 15 items, ranging from 0 to 30 . These scores will be converted to percent and categorized as the following satisfactory level $(\geq 60 \%)$ and unsatisfactory level $(<60 \%)$.

\section{The Six Dimension Scale of Nursing Performance:}

- This tool consists of 28 items in the form of "Yes" (1) and "No" (Zero) and the final score is the sum of the 28 items, ranging from 0 to 28 . These scores will be converted to percent and categorized as the following adequate performance $(\geq 60 \%)$ and inadequate performance $(<60 \%)$.

Tools Validity: Face and content validity of the study tools was assessed by jury group consisted of five experts (They are Faculty members of Community Health Nursing Department at Beni-Suef University). Jury group members judge tools for comprehensiveness, accuracy and clarity in language. Based on their recommendation, correction, addition and/or omission of some items was done.

Fieldwork: Data collection of the study was started at the beginning of March 2019, and completed by the end of June 2019. The researcher attended at the geriatric units three days per week from $9 \mathrm{am}$ to $2 \mathrm{pm}$ at Beni-Suef university hospital for all The older adult is already diagnosed with multi comorbidities disease', receiving medical and nursing care for at least 3 months. The researcher first explained the aim of the study to the participants and reassures them that information collected will be treated confidentiality and that it will be used only for the purpose of the research. Then the researcher distributes the questionnaire sheet and observe the hospital environment and nurses performance with elderly patients.

Administrative Design: An official letter requesting permission to conduct the study was directed from the dean of the faculty of nursing Beni-Suef University to director at Beni-Suef university hospital to obtain their approval to carry out this study. This letter included the aim the study and photocopy from data collection tools in order to get their permission and help for collection of data. 
Ethical Considerations: The study was conducted with careful attention to ethical standards of research and rights of participants. Verbal consent was taken from each nurse as well as patient to participate in this study. During the initial interview, the purpose of the study and the procedures were explained to the participants. The subjects were assured that all information will be confidential and will be used for the research only to assure the confidentiality of the participants. Participants will be assured that their participation in the study is voluntary and that they can refuse to participate in the study. It will be explained that there are no costs to participate in the study.

Statistical Analysis: Data entry and statistical analysis were done using (SPSS) statistical software package. Quality control was at the stage of coding and data entry. Data were presented using descriptive statistics in the form of frequencies and percentage for qualitative variables; mean and standard deviation for quantitative variable. Qualitative categorical variables were compared Chi-square (X2) test; the hypothesis that the row and column variables are independent, without indicating strength or direction of the relationship, Analysis of variance (ANOVA) test. Statistical significance was considered at $(\mathrm{P}$-value $<0.05)$.

\section{Results}

Table (1) shows the distribution of sociodemographic characteristics of studied nurses, the table shows that, the age of the studied sample was with $44.6 \pm 9.1$. The most of studied nurses are female with $76 \%$. The majority of nurses had 25:35 years (40\%). And minority of nurses was more than 45 years with $10 \%$. Related to the educational level, more than half of the studied nurses had technical institute, while only $32 \%$ of the studied nurses have university education in nursing.

Table 2: describes the distribution of studied nurses regarding their work place satisfaction. The table reveals that $(44 \%)$ of the participant reported agreement in the item "In the last year, my work has grown more interesting" (38\%) of the participant reported agreement in the item "My job is very meaningful for me", $(60 \%)$ of the participant reported partly agreement in the item "In the last year, my work has grown more interesting "My job gives me a lot of satisfaction". (60\%) I of the participant reported partly agreement in the item "have enough support from colleagues", $(40 \%)$ of the participant reported agreement in the item "I function well on a busy ward.

Table 3: show that there is a significant relation between nurse's level of satisfaction and their sex, (58.3\%) males were satisfied compared to (15.7) females satisfied. (16.7\%) unsatisfied males compared to $(28.9 \%)$ unsatisfied females. $(p<0.05)$.

Table 4: show that $(56 \%)$ of participants Promote the patients' rights to privacy. (54\%) of participants. Demonstrate knowledge of the legal boundaries of nursing. (52\%) of participants Give emotional support to family of dying patient. (48\%) of participants Accept responsibility for the level of care under his/her direction. (46\%) of participants Evaluate results of nursing care. On the other hand $(6 \%)$ of participants Give praise and recognition for achievement to those under his/ her direction, and (16\%) of participants Promote the inclusion of patient's decision and desires concerning his/her care.

Table 5: show that there is a significant relation between nurse's level of performance and their sex $(p<0.05)$. There is a significant relation between nurse's level of satisfaction and their education level. Technical institute nurse $(29.4 \%)$ has high level of performance, compared to $(31.3 \%)$ of nurses holding bachelor degree have low performance level $(\mathrm{p}<0.05)$.

Table 6: show that there is a significant relation between patient's evaluation of health qual items and their sex $(p<0.05)$ males represent $(32.6 \%)$ had negative evaluation compared to females $(42.6 \%)$, on the other hand half of males had positive evaluation compared to $(18.5 \%)$ of females. there's no a significant relation between patient's evaluation of health qual items and their education level $(p>0.05)$. There is a highly statistically significant relation between patient's evaluation of health qual items and their residence $(\mathrm{p}<0.05)$. 
Table (1): Distribution of Socio-demographic characteristics of studied nurses:

\begin{tabular}{|c|c|c|}
\hline Item & $\mathbf{N}$ & $\%$ \\
\hline Age & \multicolumn{2}{|c|}{$44.6 \pm 9.1$} \\
\hline Less than 25 & 15 & 30 \\
\hline $25-35$ & 20 & 40 \\
\hline $35-45$ & 10 & 20 \\
\hline More than 45 & 5 & 10 \\
\hline \multicolumn{3}{|l|}{ Sex } \\
\hline Male & 12 & 24 \\
\hline Female & 38 & 76 \\
\hline \multicolumn{3}{|l|}{ Educational Level } \\
\hline Technical institute & 34 & 68 \\
\hline Bachelor degree & 16 & 32 \\
\hline
\end{tabular}

Table (2): Distribution of studied nurses regarding their Workplace Satisfaction

\begin{tabular}{|c|c|c|c|c|c|c|}
\hline \multirow{2}{*}{$\begin{array}{l}\text { Statement } \\
\text { How much you enjoy your job }\end{array}$} & \multicolumn{2}{|c|}{ Agree } & \multicolumn{2}{|c|}{ Partly Agree } & \multicolumn{2}{|c|}{ Disagree } \\
\hline & $\mathbf{N}$ & $\%$ & $\mathbf{N}$ & $\%$ & $\mathbf{N}$ & $\%$ \\
\hline - My job gives me a lot of satisfaction & 11 & 22 & 30 & 60 & 9 & 18 \\
\hline - My job is very meaningful for me & 19 & 38 & 13 & 26 & 18 & 36 \\
\hline - My work gives me an opportunity to show what I'm worth & 14 & 28 & 22 & 44 & 14 & 28 \\
\hline - In the last year, my work has grown more interesting & 22 & 44 & 12 & 24 & 16 & 32 \\
\hline - It's worthwhile to make an effort in my job & 17 & 34 & 20 & 40 & 13 & 26 \\
\hline \multicolumn{7}{|l|}{ Doing your job } \\
\hline - I have enough time to deliver good care to patients & 9 & 18 & 22 & 44 & 19 & 38 \\
\hline - I have enough opportunity to discuss patient problems with colleagues & 13 & 26 & 25 & 50 & 12 & 24 \\
\hline - I have enough support from colleagues & 15 & 30 & 30 & 60 & 5 & 10 \\
\hline - I function well on a busy ward & 20 & 40 & 12 & 24 & 18 & 36 \\
\hline - I feel able to learn on the job. & 16 & 32 & 20 & 40 & 14 & 28 \\
\hline - I feel confident as a clinician. & 17 & 34 & 17 & 34 & 16 & 32 \\
\hline \multicolumn{7}{|l|}{ The people you work with } \\
\hline It's possible for me to make friends among my colleagues. & 14 & 28 & 20 & 40 & 16 & 32 \\
\hline I like my colleagues. & 17 & 34 & 23 & 46 & 10 & 20 \\
\hline - I feel that I belong to a team. & 15 & 30 & 20 & 40 & 15 & 30 \\
\hline - I feel that my colleagues like me. & 13 & 26 & 25 & 50 & 12 & 24 \\
\hline
\end{tabular}

Table (3): Association between socio-demographic data of studied nurses and level of satisfaction

\begin{tabular}{|l|c|c|c|c|c|c|c|c|c|}
\hline \multirow{2}{*}{ Item } & \multirow{2}{*}{$\mathbf{N}$} & \multicolumn{2}{|c|}{ Satisfied (13) } & \multicolumn{2}{|c|}{ Average (24) } & \multicolumn{2}{|c|}{ Unsatisfied (13) } & \multirow{2}{*}{$\mathbf{X}^{\mathbf{2}}$} & \multicolumn{1}{c|}{$\mathbf{p}$} \\
\cline { 3 - 9 } & & $\mathbf{N}$ & $\mathbf{\%}$ & $\mathbf{N}$ & $\mathbf{\%}$ & $\mathbf{N}$ & $\mathbf{\%}$ & \\
\hline Sex & & & & & & & & \\
Male & 12 & 7 & 58.3 & 3 & 25 & 2 & 16.7 & 8.6 & .01 \\
\hline Female & 38 & 6 & 15.7 & 21 & 55.2 & 11 & 28.9 & \\
\hline
\end{tabular}




\begin{tabular}{|c|c|c|c|c|c|c|c|c|c|}
\hline \multirow{2}{*}{ Item } & \multirow{2}{*}{$\mathbf{N}$} & \multicolumn{2}{|c|}{ Satisfied (13) } & \multicolumn{2}{|c|}{ Average (24) } & \multicolumn{2}{|c|}{ Unsatisfied (13) } & \multirow{2}{*}{$\mathrm{X}^{2}$} & \multirow{2}{*}{$\mathbf{p}$} \\
\hline & & $\mathbf{N}$ & $\%$ & $\mathbf{N}$ & $\%$ & $\mathbf{N}$ & $\%$ & & \\
\hline \multicolumn{8}{|l|}{ Educational level } & \multirow{3}{*}{0.3} & \multirow{3}{*}{0.8} \\
\hline Technical institute & 34 & 9 & 26.4 & 17 & 50 & 8 & 23.7 & & \\
\hline Bachelor degree & 16 & 4 & 25 & 7 & 43.7 & 5 & 31.3 & & \\
\hline
\end{tabular}

Table (4): Distribution of studied nurses in relation to The Six Dimension Scale of Nursing Performance.

\begin{tabular}{|c|c|c|c|}
\hline \multirow{2}{*}{\multicolumn{2}{|c|}{ Item }} & \multicolumn{2}{|c|}{ Yes } \\
\hline & & \multirow{2}{*}{$\mathbf{N}$} & \multirow{2}{*}{$\frac{\%}{26}$} \\
\hline 1 & Teach a patient's family members about the patient's needs by innovative method. & & \\
\hline 2 & Coordinate the plan of nursing care with the medical plan of care. & 18 & 36 \\
\hline 3 & Give praise and recognition for achievement to those under his/her direction & 3 & 6 \\
\hline 4 & Teach preventive health measure to patients and their families. & 11 & 22 \\
\hline 5 & Identity and use community resources in developing a plan of care for a patient and his/her family. & 9 & 18 \\
\hline 6 & Identify and include in nursing care plans anticipated changes in patient's conditions. & 19 & 38 \\
\hline 7 & Evaluate results of nursing care. & 23 & 46 \\
\hline 8 & Promote the inclusion of patient's decision and desires concerning his/her care. & 8 & 16 \\
\hline 9 & $\begin{array}{l}\text { Perform technical procedures: e.g. oral suctioning, tracheostomy care, IV therapy, catheter care, } \\
\text { dressing changes. }\end{array}$ & 11 & 22 \\
\hline 10 & $\begin{array}{l}\text { Adapt teaching method and materials to the understanding of the particular audience: e.g., age of } \\
\text { patient, educational background and sensory deprivation. }\end{array}$ & 13 & 26 \\
\hline 11 & Communicate a feeling of acceptance of each patient and a concern for the patient's welfare. & 15 & 30 \\
\hline 12 & Seek assistance when necessary. & 13 & 26 \\
\hline 13 & Help a patient communicate with others. & 18 & 36 \\
\hline 14 & Use mechanical devices: e.g., suction machine, glucometer, cardiac monitor, respirator & 9 & 18 \\
\hline 15 & Give emotional support to family of dying patient. & 26 & 52 \\
\hline 16 & Verbally communicate facts, ideas, and feelings to other health care team members. & 22 & 44 \\
\hline 17 & Promote the patients' rights to privacy. & 28 & 56 \\
\hline 18 & Contribute to an atmosphere of mutual trust, acceptance, and respect among health team & 21 & 42 \\
\hline 19 & $\begin{array}{l}\text { Delegate responsibility for care based on assessment of priorities of nursing care needs and the } \\
\text { abilities and limitations of available health care personnel. }\end{array}$ & 18 & 36 \\
\hline 20 & Explain nursing procedures to a patient prior to performing them. & 19 & 38 \\
\hline 21 & Guide other health team members in planning for nursing care. & 16 & 32 \\
\hline 22 & Accept responsibility for the level of care under his/her direction. & 24 & 48 \\
\hline 23 & Perform appropriate measures in emergency situations. & 21 & 42 \\
\hline 24 & Promote the use of interdisciplinary resource persons. & 22 & 44 \\
\hline 25 & Encourage the family to participant in the care of the patient. & 15 & 30 \\
\hline 26 & Demonstrate knowledge of the legal boundaries of nursing. & 27 & 54 \\
\hline 27 & Demonstrate knowledge in the ethics of nursing. & 23 & 46 \\
\hline 28 & Accept and use constructive criticism. & 16 & 32 \\
\hline
\end{tabular}


Table (5): Association between socio-demographic data of studied nurses and level of performance

\begin{tabular}{|c|c|c|c|c|c|c|c|}
\hline \multirow{2}{*}{ Item } & \multirow{2}{*}{$\mathbf{N}$} & \multicolumn{2}{|c|}{ High performance (21) } & \multicolumn{2}{|c|}{ Low performance (29) } & \multirow{2}{*}{$\mathbf{X}^{2}$} & \multirow{2}{*}{$\mathbf{P}$} \\
\hline & & $\mathbf{N}$ & $\%$ & $\mathbf{N}$ & $\%$ & & \\
\hline \multicolumn{8}{|l|}{ Sex } \\
\hline Male & 12 & 9 & 75 & 3 & 25 & \multirow{2}{*}{7.05} & \multirow{2}{*}{.007} \\
\hline Female & 38 & 12 & 31.5 & 26 & 68.4 & & \\
\hline \multicolumn{8}{|l|}{ Educational level } \\
\hline Technical institute & 34 & 10 & 29.4 & 24 & 70.5 & \multirow{2}{*}{6.9} & \multirow{2}{*}{0.008} \\
\hline Bachelor degree & 16 & 11 & 68.7 & 5 & 31.3 & & \\
\hline
\end{tabular}

Table (6): Association between socio-demographic data of the studied sample and their evaluation of health qual items.

\begin{tabular}{|c|c|c|c|c|c|c|c|c|}
\hline & \multicolumn{2}{|c|}{ Negative38 } & \multicolumn{2}{|c|}{ Average29 } & \multicolumn{2}{|c|}{ Positive33 } & \multirow[t]{2}{*}{$X^{2}$} & \multirow[t]{2}{*}{$\mathbf{P}$} \\
\hline & $\mathbf{N}$ & $\%$ & $\mathbf{N}$ & $\%$ & $\mathbf{N}$ & $\%$ & & \\
\hline \multicolumn{9}{|l|}{ Gender } \\
\hline Male 46 & 15 & 32.6 & 8 & 17.4 & 23 & 50 & \multirow{2}{*}{12.07} & \multirow{2}{*}{.002} \\
\hline Female54 & 23 & 42.6 & 21 & 38.9 & 10 & 18.5 & & \\
\hline \multicolumn{9}{|c|}{ Educational Level } \\
\hline Illiterate24 & 7 & 29.2 & 6 & 25 & 11 & 45.8 & \multirow{4}{*}{4.66} & \multirow{4}{*}{.5} \\
\hline Primary31 & 10 & 32.3 & 10 & 32.3 & 11 & 35.5 & & \\
\hline Secondry33 & 15 & 45.6 & 9 & 27.3 & 9 & 27.3 & & \\
\hline University 12 & 6 & 50 & 4 & 33.3 & 2 & 16.7 & & \\
\hline \multicolumn{9}{|l|}{ Residence } \\
\hline Rural67 & 17 & 25.4 & 25 & 37.3 & 25 & 37.3 & \multirow{2}{*}{14.5} & \multirow{2}{*}{.0007} \\
\hline Urban33 & 21 & 63.7 & 4 & 12.1 & 8 & 24.2 & & \\
\hline
\end{tabular}

\section{Discussion}

Population aging is a great challenge for the health care systems. Although the health status of older people is improving over time now and the life expectancy is increasing, still, with aging, the prevalence of disability, frailty, cancer, and chronic diseases is expected to increase, especially with the large growth in the oldest old group. The older the person is, the more likely to face a compounding of multiple health, psychological and social problems that make accurate medical diagnosis and proper medical management difficult ${ }^{(3)}$.

Elderly people have high risk for functional impairments with inability to perform ordinary activities of daily living and activities related to household management termed instrumental activities of daily living. In addition to the general health services, whether governmental or private, that are available for the use by the elderly, there are other special services for the older people that have developed in Egypt. Changes in the health of older persons were already detectable decades before and should have prompted radical changes in the structure and function of our system of health and social protection at that time. We come to this enormous challenge unprepared and need good quality system to overcome these changes ${ }^{(2)}$. So the current study aimed to assess the quality of health care delivered to old age and factors affecting quality of health care.

Regarding distribution of socio-demographic characteristics of studied nurses, the current study revealed that the most of studied nurses are female. The majority of nurses had 25:35 years. Related to the educational level, more than half of the studied nurses had technical institute.

This result was in agreement with ${ }^{(11)}$ that conducted 
entitled "Factors affecting access to oral health care among adults" and found that majority of participants were female, and their experience had experience from 5 to 10 years. Also, this result was in agreement with ${ }^{(12)}$ that conducted entitled "An international comparison of factors affecting quality of life among patients with congestive heart failure" and found that majority of participants had technical institute. Regarding nurses' work place satisfaction, the current study revealed that nearly half of the participant reported agreement in the item "In the last year, my work has grown more interesting". More than one third of the participant reported agreement in the item "My job is very meaningful for me", three fifth of the participant reported partly agreement in the item "have enough support from colleagues", two fifth of the participant reported agreement in the item "I function well on a busy ward".

In the same line, this result was accordance with ${ }^{(13)}$ that conducted entitled "Evaluation of factors affecting patient satisfaction with health care services" and found that majority of participants were interested with their work, and had good relationship with others. Conversely, this result was in disagreement with ${ }^{(14)}$ that conducted entitled "Factors affecting patient's satisfaction in outpatient clinics" and found that majority of participants had poor relationship with others and hadn't support from member's organization.

Regarding nurses' work place satisfaction, the current study revealed that more than one quarter of the participants were satisfied according to work place satisfaction. This result was in congruence with (14) that conducted entitled "Systemic factors affecting the technical quality of healthcare" and found that minority of participants were satisfied about their work place. Conversely, this result was in disagreement with (16) that conducted entitled "Quality indicators of nutritional care practice in elderly care" and found that majority of participants were satisfied about their work place.

Regarding association between socio-demographic data of studied nurses and level of satisfactions, the current study revealed that there is a significant relation between nurse's level of satisfaction and their sex.

This result was in congruence with ${ }^{(17)}$ that conducted entitled "Structure and process quality as predictors of satisfaction with elderly care" and found that majority of participants had significant relation between nurse's level of satisfaction and their gender. Conversely, this result was in disagreement with (18) that conducted entitled "Self-perceived quality of health and satisfaction by elderly seen by the Family Health Strategy team" and found that majority of participants had significant relation between nurse's level of satisfaction and their ages.

Regarding distribution of studied nurses in relation to the six-dimension scale of nursing performance, the current study revealed that more than half of participants Promote the patients' rights to privacy, demonstrate knowledge of the legal boundaries of nursing and give emotional support to family of dying patient. Nearly half of participants accept responsibility for the level of care under his/her direction, and evaluate results of nursing care.

This result was in agreement with ${ }^{(17)}$ that conducted entitled "Safeness and treatment mitigate the effect of loneliness on satisfaction with elderly care" and found that majority of participants had good relation with their patients. Also, this result was accordance with ${ }^{(19)}$ that conducted entitled "Assessing bus transit service from the perspective of elderly passengers in Harbin" and found that majority of participants keep privacy of their patients and them work with their patients at holistic case.

Regarding distribution of studied sample according to their performance, the current study revealed that more than half of participants had unsatisfied level according to their performance. More than two fifth of participants had satisfied level according to their performance.

This result was in congruence with ${ }^{(20)}$ ) that conducted entitled "The effects of job satisfaction and ethical climate on service quality in elderly care" and found that half of participants had satisfied level of performance. Conversely, this result was in disagreement with ${ }^{(21)}$ that conducted entitled "Factors Affecting Quality of care in Primary Health Care Centers" and found that majority of participants had unsatisfied level of performance.

Regarding association between socio-demographic data of studied nurses and level of performance, the current study revealed that there is a significant relation between nurse's level of performance and their sex, three quarter of male nurses had high level of performance.

This result was accordance with ${ }^{(22)}$ that conducted entitled "Factors affecting quality of health service and patient satisfaction in community health centers" 
and found that majority nurses had high level of performance. Also, this result was in agreement with ${ }^{(23)}$ that conducted entitled "Assessing the Factors Affecting Quality of Health Care Provision at Health Centre" and found that majority nurses had a significant relation between nurse's level of performance and their gender.

Regarding perception of nurses about management and leadership skills, the current study revealed that three fifth of participants reported that their managers and leaders give them the opportunity to identify rules and regulations. This result was in agreement with ${ }^{(24)}$ that conducted entitled "Psychological and socio-economic factors affecting social sustainability through impacts on perceived health care quality and public health" and found that majority of participants had leader were understood with them.

Regarding perception of nurses about Progress and career advancement, the current study revealed that nearly one third of participants reported that there are good opportunities for continuing education at hospital, three fifth of participants reported that never there are training courses that allow progress and improvement.

This result was supported with ${ }^{(25)}$ that conducted entitled 'Staff Nurses' Perceptions of Their Nurse Managers' Transformational Leadership Behaviors and Their Own Structural Empowerment" and found that minority of nurses got on training courses at hospital. Conversely, this result was in disagreement with ${ }^{(26)}$ that conducted entitled "Nurses perception of management in one Referral Hospital" and found that majority of nurses got on training courses at hospital.

Regarding perception of nurses about responsibility at work, the current study revealed that half of participants reported that managers and leaders' responsibilities are known to all, and two fifth of participants reported that never involved in making decisions

This result was accordance with ${ }^{(27)}$ that conducted entitled Clinical Nurses' Perceptions of Authentic Nurse Leadership and Healthy Work Environment and found that majority of managers had all responsibility and their nurses not involved in decision making. Conversely, this result was in disagreement with ${ }^{(28)}$ that conducted entitled "How staff nurses perceive the impact of nurse managers' leadership style in terms of job satisfaction" and found that majority of nurse manager involved their nurses in decision making.

\section{Conclusion}

The current study concluded that: Nearly half of nurses (48\%) had average level of satisfaction and $58 \%$ of them had unsatisfied level according to their performance while $42 \%$ of them had satisfied level according to their performance. $40 \%$ of nurses had average level of perception of management and leadership skills, and $36 \%$ of them had negative level of perception, while $24 \%$ of them had positive level of perception. $38 \%$ of patients had fair level about their evaluation, $33 \%$ of them had excellent level about their evaluation to quality of health care, and $29 \%$ of them had average level and $41 \%$ of them had negative level of satisfaction.

Recommendation: In the light of results of this study, the following recommendations were suggested:

- Periodic assessment of nurses' perception about quality of care of elderly patient.

- Regular implementation of training programs regarding quality of care.

- Provide continuous support for elderly to enhance their quality of care

- Investigating the effect of quality of care on elderly satisfaction.

- Further studies should be conducted in different settings.

Ethical Clearance: Taken from ethical research committee, faculty of nursing Beni-Suef University, Egypt.

Conflict of Interest: No conflict of interest

Source of Funding: Self-funding

\section{References}

1. Ghayth EI, Fahmy HD, El-moghrab NM, El-Aziz A, Mahmoud N. Knowledge and Reported Practice Among Elderly With Oral and Dental Problems at Assiut City, Egypt. Assiut Scientific Nursing Journal. 2019 Jun 1;7(17):102-12.

2. Abou El-Magd MM, Zaki MF. Productivity and quality of some broccoli cultivars in eastern Egypt under different planting dates. Middle East Journal of Applied Sciences. 2017 Oct;7(4):848-56.

3. El-masry R, Elwasify M, Khafagy M. Adaptation and Reliability of the Arabic Version of Alzheimer's 
Disease Knowledge Scale (ADKS) among sample of middle aged and elderly Egyptians attending outpatient clinics in Mansoura. The Egyptian Journal of Community Medicine. 2018 Oct;36:5969.

4. Lewis LN. Egypt's future depends on agriculture and wisdom. Peleman Industries/UniBook (webpublishing); 2011 May.

5. Armstrong JJ, Goldfarb AM, Instrum RS, MacDermid JC. Improvement evident but still necessary in clinical practice guideline quality: a systematic review. Journal of clinical epidemiology. 2017 Jan 1;81:13-21.

6. Fedarko NS. Theories and mechanisms of aging. InGeriatric Anesthesiology 2018 (pp. 19-25). Springer, Cham.

7. Imagama S, Hasegawa $\mathrm{Y}$, Ando K, Kobayashi $\mathrm{K}$, Hida $\mathrm{T}$, Ito $\mathrm{K}$, Tsushima $\mathrm{M}$, Nishida $\mathrm{Y}$, Ishiguro N. Staged decrease of physical ability on the locomotive syndrome risk test is related to neuropathic pain, nociceptive pain, shoulder complaints, and quality of life in middle-aged and elderly people-The utility of the locomotive syndrome risk test. Modern Rheumatology. 2017 Nov 2;27(6):1051-6.

8. Katsoulis M, Benetou V, Karapetyan T, Feskanich D, Grodstein F, Pettersson-Kymmer U, Eriksson S, Wilsgaard T, Jørgensen L, Ahmed LA, Schöttker B. Excess mortality after hip fracture in elderly persons from Europe and the USA: the CHANCES project. Journal of internal medicine. 2017 Mar;281(3):300-10.

9. Leshabari KM, Biswas AK, Gebuis E, Leshabari SC, Ohnishi M. Challenges in morbidity and mortality statistics of the elderly population in Tanzania: a call to action. Quality in Ageing and Older Adults. 2017 Sep 11.

10. World health organization, quality health care; research and statistics, Washington, DC: National Academies Press. 2018.

11. Almutlaqah MA, Baseer MA, Ingle NA, Assery MK, Al Khadhari MA. Factors affecting access to oral health care among adults in Abha City, Saudi Arabia. Journal of International Society of Preventive \& Community Dentistry. 2018 Sep;8(5):431.

12. Roy B, Wolf JR, Carlson MD, Akkermans R, Bart B, Batalden P, Johnson JK, Wollersheim
$\mathrm{H}$, Hesselink G. An international comparison of factors affecting quality of life among patients with congestive heart failure: A cross-sectional study. PloS one. 2020 Apr 8;15(4):e0231346.

13. Girgin R, Demirkıran ED, Y1lmaz G. Evaluation of Factors Affecting Patient Satisfaction with Health Care Services: A Cross-sectional Study in an Endourology Clinic.J Urol Surg 2019;6(4):278-282.

14. AlRyalat SA, Ahmad W, Abu-Abeeleh M, AbdAljawad T, Salem M, Ahmad E, Hamdan A. Factors affecting patient's satisfaction in outpatient clinics in Jordan: cross-sectional study. Journal of Hospital Management and Health Policy. 2019;3(2):1-6.

15. Zigani Z, BICABA A, Sanon A, Sawadogo S. Systemic factors affecting the technical quality of healthcare in results-based financing in Burkina Faso.

16. Josefsson MS, Nydahl M, Persson I, Sydner YM. Quality indicators of nutritional care practice in elderly care. The journal of nutrition, health \& aging. 2017 Nov 1;21(9):1057-64.

17. Kajonius PJ, Kazemi A. Safeness and treatment mitigate the effect of loneliness on satisfaction with elderly care. The Gerontologist. 2016 Oct 1;56(5):928-36.

18. Rigo L, Garbin RR, Rodrigues JL, Menezes-Júnior LR, Paranhos LR, Barelli C. Self-perceived quality of health and satisfaction by elderly seen by the Family Health Strategy team. Einstein (São Paulo). 2017 Dec;15(4):428-34.

19. Yuan Y, Yang M, Wu J, Rasouli S, Lei D. Assessing bus transit service from the perspective of elderly passengers in Harbin, China. International Journal of Sustainable Transportation. 2019 Nov 26;13(10):761-76.

20. Chao CY, Ku PY, Wang YT, Lin YH. The effects of job satisfaction and ethical climate on service quality in elderly care: the case of Taiwan. Total Quality Management \& Business Excellence. 2016 Mar 3;27(3-4):339-52.

21. Dangmei J, Singh AP. Factors Affecting Quality Of Care In Primary Health Care Centres With Special Reference To Anuppur District (MP). Healthcare, Quality of Care. 2019.

22. Widayati MY, Tamtomo D, Adriani RB. Factors affecting quality of health service and patient satisfaction in community health centers in North Lampung, Sumatera. Journal of Health Policy and 
Management. 2018 Mar 7;2(2):165-75.

23. Adriko B. Assessing The Factors Affecting Quality Of Health Care Provision At Ayivuni Health Centre Three Ayivuni Sub-County Arua District-Uganda (Doctoral dissertation, CIU).

24. Vuong QH, Vuong TT, Ho TM, Nguyen HV. Psychological and socio-economic factors affecting social sustainability through impacts on perceived health care quality and public health: The case of Vietnam. Sustainability. 2017 Aug; 9(8):1456.

25. Khan BP, Griffin MT, Fitzpatrick JJ. Staff Nurses' Perceptions of Their Nurse Managers' Transformational Leadership Behaviors and Their Own Structural Empowerment. JONA: The Journal of Nursing Administration. 2018 Dec 1;48(12): 609-14.

26. Lunkuse EJ. Neonatal pain: nurses perception of management in one Referral Hospital in Rwanda (Doctoral dissertation, University of Rwanda).

27. Raso R, Fitzpatrick JJ, Masick K. Clinical Nurses' Perceptions of Authentic Nurse Leadership and Healthy Work Environment. JONA: The Journal of Nursing Administration. 2020 Sep 1;50(9):489-94.

28. Morsiani G, Bagnasco A, Sasso L. How staff nurses perceive the impact of nurse managers' leadership style in terms of job satisfaction: a mixed method study. Journal of Nursing Management. 2017 Mar; 25(2):119-28. 